\title{
IoT based Real-Time Pulse Monitoring and Geolocation Alerting System with Data Analysis
}

\author{
Prateek Konduru [1], Naga Surya $S_{[2]}$, \\ Department of Electronics and Communication Engineering, \\ PES University, Dwarka Nagar, Banashankari, Bengaluru, \\ Karnataka 560085
}

\begin{abstract}
With the wise enhancements in the advancements and scaling down of actuators and sensors, there have been different endeavors to use the most recent advances in different regions to improve the characteristics of human life. One such fundamental region of the exploration that has been seen is the reception of advancements is the division of healthcare. The general population needing administrations in medicinal services think that it's costly, this is especially valid in a large portion of the developing nations. Accordingly, the fundamental target of this venture is to structure a remote healthcare system framework. It involves three significant parts. The initial segment being, recognition of one's vitals, utilizing sensors, second is to send information to cloud databases and the last part is to give the information to remote surveys. Remote survey of this information empowers specialists to screen one's wellbeing progress far from the restorative consideration focus. IoT ideas have been utilized to interconnect accessible medical assets and offer solid and powerful human services administration. In this project, we have introduced the engineering of IoT, modified for human services applications. The point of the venture is to think of a Remote Pulse Monitoring System that can be made with effectively accessible sensors with the end goal of making it reasonable if it somehow happened to be mass delivered. Henceforth the proposed engineering gathers the sensor information through a microcontroller and sends it to the database, where it is additionally handled and broke down for survey remotely different activities because of the dissected information, can be sent to the specialist through an SMS alert if there should be an occurrence of any sort of crisis
\end{abstract}

Keywords - IoT, Databases, Microcontrollers, Mobile application, Geolocation.

\section{INTRODUCTION}

Here the fundamental target is to plan a Remote Patient Heart Monitoring System to analyze the wellbeing state of the patients. Giving consideration and wellbeing help to hypertensive patients at basic stages. Propelled medical offices have turned out to be one of the serious issues in the cutting edge quickly developing the world. In medical clinics where numerous patients, whose physical conditions must be checked much of the time as a piece of an analytic system, the requirement for a financially savvy and quick reacting ready component is unavoidable. Legitimate execution of these

frameworks can give convenient admonitions and the area of the patient to the medical staff and specialists and their administration can be initiated in the event of extreme restorative crises. Present-day frameworks use sensors that are designed to the PC/framework beside the bed. The utilization of these sensors distinguishes the states of the patient and the information is gathered and exchanged utilizing a microcontroller or an IC. Specialists or attendants need to visit these patients much of the time to look at one's present condition. Moreover, the utilization of different microcontrollers based smart frameworks gives abnormal state materialism in clinics, where numerous patients are habitually checked. For this, here we utilize the possibility of essential system innovations with remote materialness, giving every patient a one of a kind ID by which the specialist can without much of a stretch distinguish the patient and one's status of pulse parameters and area. Utilizing this proposed framework, information can be sent remotely to the patient checking database, permitting the ceaseless observation of the patient's pulse. Contributing precision in estimations of pulse, location coordinates, and giving security in a legitimate ready instrument give this framework a magnificent dimension of consumer loyalty and minimal effort usage. Hence, the patient can take part in his everyday day by day exercises in an agreeable environment where the diversions of designed sensors are absent and travel anyplace however one sees fit. Heart monitoring equipment can be effectively actualized utilizing basic interfaces of the sensors with a microcontroller and GPS sensor and can viably be utilized for medicinal services checking. This will permit the advancement of such ease gadgets dependent on normal human-PC interfaces. The framework we proposed here is effective in observing the pulse parameters of numerous quantities of laid up patients and after that in cautioning the concerned medical experts with the GPS coordinates if these parameters skip over its predefined basic threshold limit. Consequently, remote checking and control allude to a field of modern computerization that is entering a new era with the improvement of remote detecting gadgets. The IoT, Internet of Things stage offers a promising and certain innovation to accomplish the medicinal services benefits and can additionally improve the medical administration frameworks. IoT wearable frameworks can be utilized to gather the genuinely necessary data of the end-user or patient and its well-disposed condition and impart such data remotely, where it is processed or stored for tracking the history of the user with the location. Such connectivity with external devices and services will allow for taking the preventive measure (e.g., upon foreseeing an upcoming heart stroke/attack) or provide immediate care (e.g., when a user is traveling and needs immediate attention based on user location coordinates). 


\section{LITERATURE SURVEY}

\section{A. IoT based Heart Attack Detection, Heart Rate, and temperature monitor}

The Internet of Things (IoT) is the intercommunication of implanted gadgets utilizing organizing innovations. The IoT will be one of the significant patterns later, can influence the systems administration, business, and correspondence. Proposing a remote detecting parameter of the human body which comprises of heartbeat and temperature. The parameters that are utilized for detecting and checking will send the information through remote sensors. Including an electronic

watching monitors the ordinary wellbeing status of a patient. The detecting information will be consistently gathered in a database and will be utilized to advise the patient regarding any

concealed issues to experience conceivable analysis.

\section{B. Sensor-based healthcare information system}

In the course of the most recent couple of years, the persuading forward strides in the improvement of the Internet of Things (IoT)- empowering arrangements are prodding the approach of novel and intriguing applications. The present medicinal services framework is the absence of security and continuous checking. In the wake of this propensity, this paper proposes a novel, IoT-mindful, brilliant engineering for programmed checking and following of patients from their home itself. Remaining consistent with the IoT vision, we propose an Automation Healthcare System (AHS). The proposed AHS is to research propelled home human services administrations. Information created in AHS imparted to specialists and patients through IoT. The framework uses IoT telemetry to transmit information from sensors to a remote screen. This paper talks about ongoing advances in the wearable sensor's medicinal services framework to screen temperature, pulse, and the vitality proficient steering. The framework gives security and continuous checking.

\section{Remote Health Monitoring System through IoT}

This paper accepts with progress in advances, it very well may be normal that the accessibility of the internet is ubiquitous. Likewise, ease sensors and ICs are anything but easy to interface with any gadgets to serve data all around with IoT. Furthermore, these sensors have low power utilization ability with the execution of numerous huge wellbeing estimation apparatus. This paper portrays a framework/setup that can be utilized for remote observing of a patient's wellbeing condition and make important strides in like manner. The fundamental goal of this framework was to consequently accumulate information from sensors appended to the patient's self and store the obtained information into the cloud for sometime later that can help specialists to remote wellbeing observing of the patient. This paper likewise depicts the medical clinic the executives ready to screen more patients at any example of time. The framework depicted in this paper additionally helps the watchmen of the patients to know the wellbeing data of the patient
III. PROPOSED ARCHITECTURE

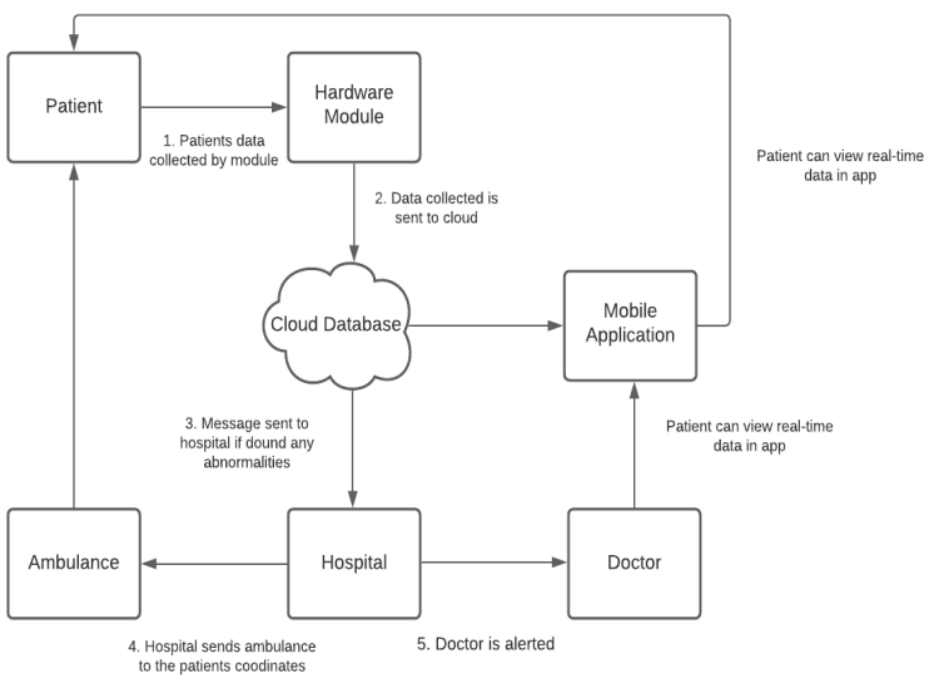

Figure 1: Architecture

The main objective is to design not only a heart rate monitoring system but also an alerting system that provides the necessary data to the nearest Hospital and person of contact whenever the readings are above or below a certain threshold value. It also provides the necessary GPS location coordinates of the patient on Google maps so that necessary services are reached to the patient in the so-called golden hour.

\section{COMPONENTS}

\section{A. Pulse Sensor}

The pulse sensor has two sides, on one side of the sensor the LED is placed along with an ambient light sensor and on the other side, there is a circuitry. This circuitry is responsible for the amplification and noise cancellation of the signal changes. The LED on the front side of the sensor is placed over a vein of the patient body. This can either be on the patient ear tip or fingertips, but the sensor should be placed directly on top of the vein so that LED emitted light falls directly on the vein. The reason being veins will have blood flow inside them, only when the heart is pumping. So, by monitoring the blood flow through the veins, one can monitor the heart rate or beats. If the flow of blood is detected, then the ambient light sensor will receive intense light concerning the emitted light at the initial stage. Since this light will be reflected by the blood, this minor change in received light is analyzed over time, to determine one's heartbeat data.

\section{Pin Configuration}

\begin{tabular}{|l|l|l|l|}
\hline $\begin{array}{l}\text { Pin Name on the } \\
\text { sensor }\end{array}$ & $\begin{array}{l}\text { Pin } \\
\text { Name }\end{array}$ & $\begin{array}{l}\text { Wire } \\
\text { Color }\end{array}$ & Description \\
\hline S & Signal & Brown & Pulsating output signal. \\
\hline+ & Vcc & Red & $\begin{array}{l}\text { Connect to the }+5 \mathrm{~V} \text { supply } \\
\text { voltage }\end{array}$ \\
\hline- & Ground & Orange & $\begin{array}{l}\text { Connect to the ground of the } \\
\text { system }\end{array}$ \\
\hline
\end{tabular}

Table 1: Pulse sensor configuration 


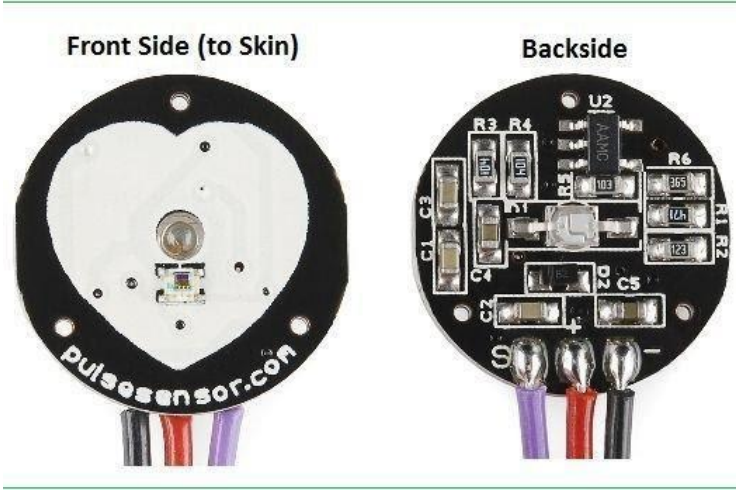

Figure 2: Pulse Sensor

B. Identify Neo-6m GPS Module

Ublox Neo-6m is used for getting the global positioning system (GPS) coordinates of the patient with the timestamp. Neo-6m module has an external antenna and a built electrically erasable programmable read-only memory (EEPROM). It uses the RS232 TTL interface. Neo-6m is set to

a default baud rate of 9600 bps. It works with the standard National Marine Electronics Association (NMEA). Neo-6m communicates serially with the esp8266 module through the Tx and Rx pins. The raw GPS data is in sentences of NMEA. NMEA sentences start with the $\$$ character, and each data field is separated by a comma. The \$GPGGA is the basic GPS NMEA message, that provides a 3D location and accuracy data. Having the \$GPGGA sentence one can collect the GPS location coordinate data. A typical \$GPGGA sentence is shown below

\$GPGGA,110617.00,41XX.XXXXX,N,00831.54761,W,1,05 ,2.68,129.0,M,50.1,M, $* 42$

Each comma-separated field provides a different set of data namely

1. 110617 - Represents the time at which the fix location was taken, 11:06:17 UTC

2. 41XX.XXXXX, N - Represents Latitude 41 degree XX.XXXXX' N

3. 00831.54761, W - Represents Longitude 008 degree 31.54761' W

4. 1 - Represents fix quality $(0=$ invalid; $1=$ GPS fix; $2=$ DGPS fix; 3 = PPS fix; 4 = Real-Time Kinematic; 5 = Float RTK; 6 = estimated (dead reckoning); 7 = Manual input mode; $8=$ Simulation mode)

5. 05 - Represents the number of satellites being tracked

6. 2.68 - Represents Horizontal dilution of position

7. 129.0, M - Represents Altitude in meters above the sea level

8. 50.1, M - Represents Height of geoid (mean sea level) above WGS84 ellipsoid

9. empty field - Represents time in seconds since the last DGPS update

10. empty field - Represents DGPS station ID number 11. $* 42-$ Represents the checksum data which always begins with *

Pin configuration
\begin{tabular}{|l|l|l|}
\hline $\begin{array}{l}\text { Pin Name on the } \\
\text { sensor }\end{array}$ & Pin Name & Description \\
\hline Vcc & Supply & connect to 5v supply voltage \\
\hline Rx & Receive pin & $\begin{array}{l}\text { Tx pin defined in the software } \\
\text { serial }\end{array}$ \\
\hline T & $\begin{array}{l}\text { Transmission } \\
\text { pin }\end{array}$ & $\begin{array}{l}\text { Rx pin defined in the software } \\
\text { serial }\end{array}$ \\
\hline GND & Ground & The ground of the system \\
\hline
\end{tabular}

Table 2: Neo 6m GPS module configuration

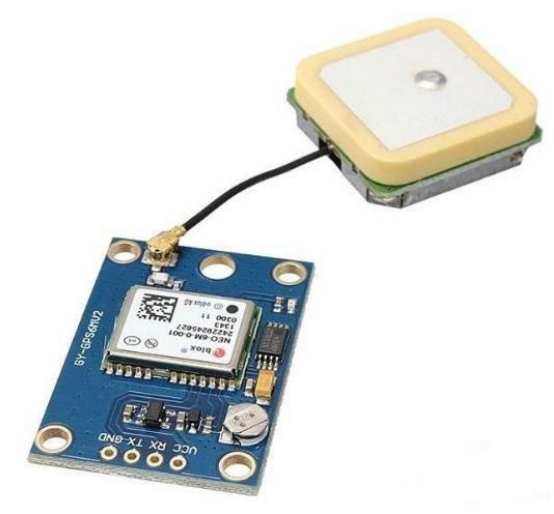

Figure 3: GPS Module

\section{Arduino Microcontroller}

Arduino Uno is a microcontroller board based on the ATmega328P. It has 14 digitals input/output pins (of which 6 can be used as PWM outputs), 6 Analog inputs, a $16 \mathrm{MHz}$ quartz crystal, a USB connection, a power jack, an ICSP header, and a reset button. It contains everything needed to support the microcontroller; simply connect it to a computer with a USB cable or power it with an AC-to-DC adapter or battery to get started.

Starting clockwise from the top center:

1. Analog Reference pin

2. Digital Ground

3. Digital Pins 2-13

4. Digital Pins 0-1/Serial In/Out - TX/RX (dark green) These pins cannot be used for

digital i/o (digitalRead and digitalWrite) if you are also using serial communication (e.g.Serial.begin).

5. Reset Button - S1

6. In-circuit Serial Programmer

7. Analog In Pins 0-5

8. Power and Ground Pins

9. External Power Supply In (9-12VDC) - X1

10. Toggles External Power and USB Power (place jumper on two pins closest to desired supply) - SV1

11. USB (used for uploading sketches to the board and for serial communication between the board and the computer; can be used to power the board) 


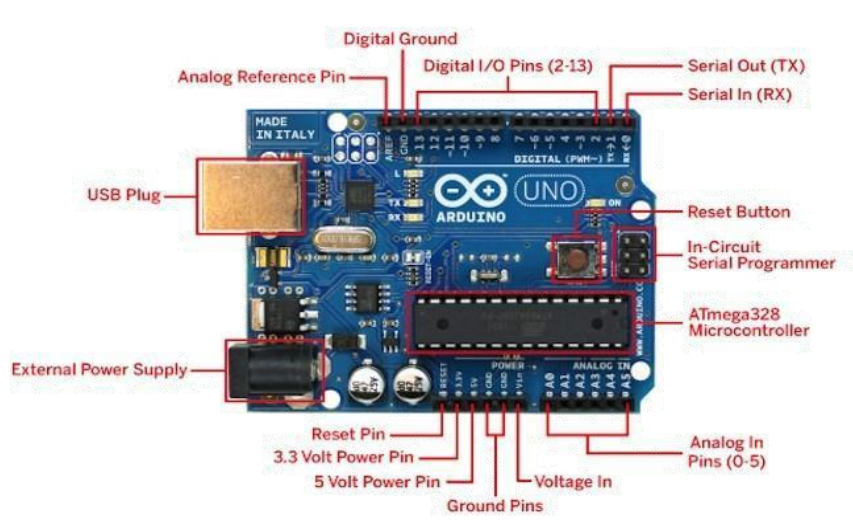

Figure 4: Arduino Microcontroller

\section{NodeMCU}

The NodeMCU ESP8266 Wi-Fi Module is a self-contained SOC with an integrated TCP/IP protocol stack that can give microcontroller access to your Wi-Fi network or act as a mini microcontroller. The ESP8266 is capable of either hosting an application or offloading all Wi-Fi networking parameters from other application processors. The ESP8266 module comes pre-programmed AT command set firmware, meaning one can interface it to an Arduino device and get a Wi-Fiability as a Wi-Fi Shield offers. The ESP8266 module is a cost-effective board. This module has a powerful onboard processing and storage capability that allows it to be integrated

directly with the sensors and actuators through GPIOs with minimal development up-front. Its high degree of integration allows for the minimal external circuitry, including the frontend module which is designed to occupy a very minimal PCB area.

\begin{tabular}{|l|l|}
\hline Size & $\begin{array}{l}25.4 * 48.26 * 3 \mathrm{~mm} \\
( \pm 0.2 \mathrm{~mm})\end{array}$ \\
\hline Certification & $\begin{array}{l}\text { FCC/CE- } \\
\text { RED/IC/TELEC/KCC/S } \\
\text { RRC/NCC/BQB } / \\
\text { RoHS/REACH }\end{array}$ \\
\hline SPI Flash & $32 \mathrm{Mbit}($ default $)$ \\
\hline Support Interface & $\begin{array}{l}\text { UART/GPIO/ADC/DAC/ } \\
\text { SDIO/SD }\end{array}$ \\
\hline $\begin{array}{l}\text { Integrated Crystal } \\
\text { Oscillator }\end{array}$ & $40 \mathrm{MHz}$ crystal oscillator \\
\hline I/O Port & 38 \\
\hline Antenna & Onboard Antenna \\
\hline
\end{tabular}

Table 3: Technical Specifications of NodeMCU

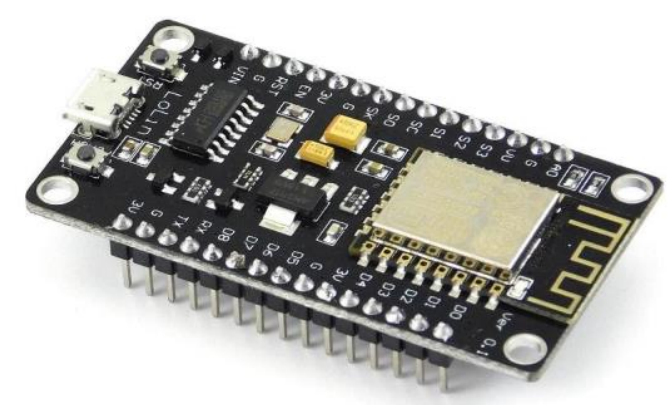

Figure 5: NodeMCU

\section{REQUIREMENT ANALYSIS}

A. Functional Requirements

- Location Tracking: The application must have track location options with which doctors or guardians can follow the area of the patient.

- Location sender: Hardware must have a GPS module to fetch location coordinates which can be used to follow the area of the patient.

- Messaging Service: Software must have a messaging API which sends SMS alert messages to doctor and guardians on any crises. And application must send email alerts upon any emergencies.

- The application must have a voice to text converter for visually disabled users

\section{B. Non-Functional Requirements}

Non-functional requirements are not directly related to the functional behavior of the system.

- The mobile application must be user-friendly, simple, and interactive.

- The user interface is designed in such a way that novice users with little knowledge of Mobile apps, should be able to access this application.

- Users are required to have some knowledge regarding google maps.

C. Software Specifications

- Operating System: Windows 7 or higher

- Platform: IoT Cloud

- IDE: Arduino 1.8.9

- Database: Firebase

- Technologies used: C, Python

D. Hardware Specifications

- Microcontroller: NODEMCU - ESP8266 Wi-Fi

Development Board

- Sensors: Pulse, GPS

- Processor: Pentium IV or higher

- Processor speed: $1.6 \mathrm{GHz}$

- RAM: 512 MB or higher

- Disk Space: $250 \mathrm{MB}$ or higher 


\section{DEVICE DESIGN}

\section{A. System Design}

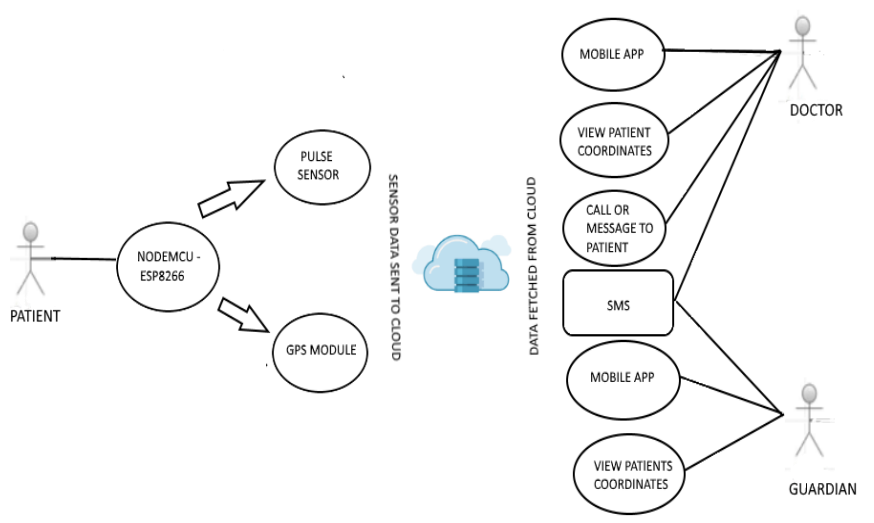

Figure 6: Use case Diagram

This project has been developed with an Arduino microcontroller connected with sensors that are attached to the patient. All the sensors and location data are sent from the microcontroller to the database into the cloud. A doctor or guardian can open the application to monitor a patient's data at any point in time. In case of emergencies, like a heartbeat spike an SMS and email alert sent to the doctor and guardian's mobile and email respectively. And at any point in time either a doctor or guardian can open the application and can track a patient's location which would help medical services to send appropriate help in case of emergencies.

\section{B. Circuit Design}

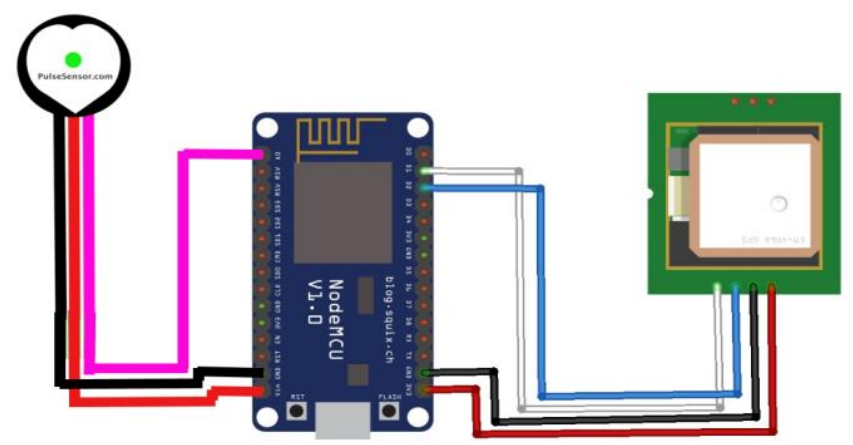

Figure 7: Circuit Diagram

In the above image, a complete device setup includes a NodeMCU board with a power supply attached to it. The microcontroller relates to all the sensors which include the Pulse sensor and GPS module is connected which is used to send sensor data into the cloud and fetch location coordinates of the patient respectively of information as soon as the device is turned on which includes location coordinates and HTTP protocols which shows the network connect procedure. In case the device, unable to connect to the network, we could see the command at which device currently halted and can be used to diagnose the issue. And finally, once the device is connected to the network, it displays all the patient information on it along with any irregularities of patient vitals

\section{Cloud Database Design}

The Firebase Database is a Real-time cloud-facilitated and NoSQL database that lets the client store and match up information continuously. Firebase is created, advertised, and bolstered by Google. It incorporates the accompanying highlights in the project, we have used a Firebase cloud which is in Tree format. One child stores the patient's sensor data and the other table stores longitude and latitude of the patient's location.

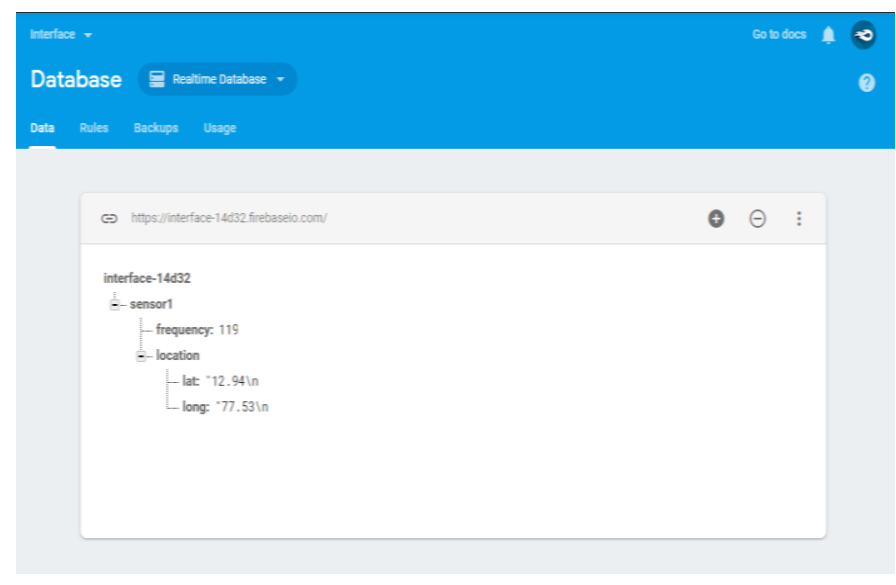

Figure 8: Cloud Database Preview

\section{Application Interface Design}

The Interface App is designed on the Android studio. The app is made to connect to the Arduino via firebase which allows us to send or receive data to and from the internet without human intervention. The app contains four screens:

- Mobile App Home Page

- Patient's Monitoring Page

- Track Patient Location Page

- Special Feature for Visually Disabled

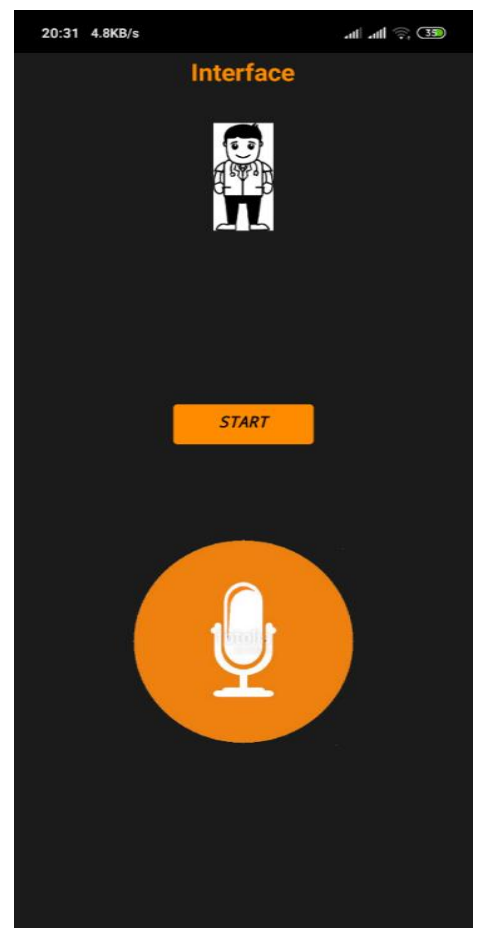



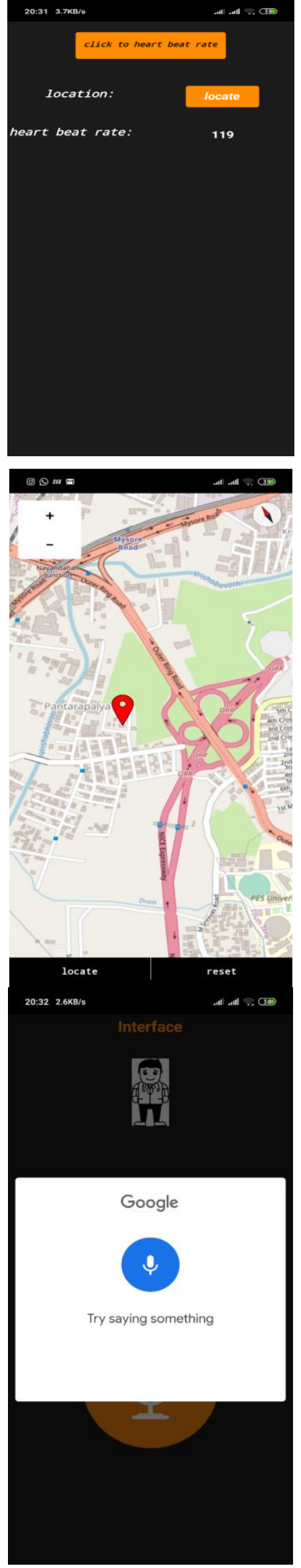

Figure 9: Application Interface Preview
E. SMS Service Design

Twilio API: Cloud sends SMS alert using Twilio API

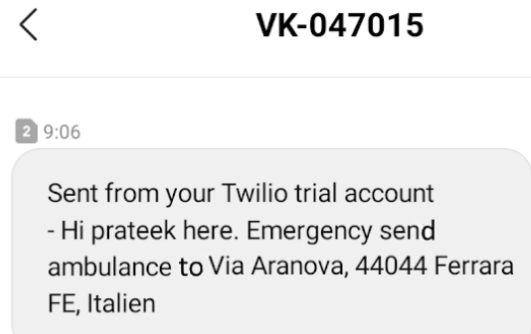

Figure 10: SMS Preview

\section{PERFORMANCE TESTING}

Following are the scenarios where testing can be carried on IoT framework based on performance.

1. Server to gadget correspondence

2. Server to Server correspondence

3. Gadget to Gadget correspondence

As per the above scenarios and focusing on the scope of this project, performance test cases tested on this project are mentioned below.

\section{A. Test Objectives: The time taken to send data to the cloud}

\begin{tabular}{|l|l|l|}
\hline TEST & OUTPUT SPECIFICATION & OPTIMAL \\
\hline $\begin{array}{l}\text { The time taken } \\
\text { to } \\
\text { send sensor } \\
\text { data to the } \\
\text { cloud. }\end{array}$ & $\begin{array}{l}\text { The microcontroller sends data every 15 } \\
\text { seconds to the cloud. Here network plays an } \\
\text { important role and the time taken to send } \\
\text { each record is <200ms including response } \\
\text { time. But if there is an issue with network } \\
\text { bandwidth then performance will be } \\
\text { deteriorated as the system takes additional to } \\
\text { check network connectivity and send data to } \\
\text { the cloud. }\end{array}$ & TRUE \\
\hline
\end{tabular}

Table 4: Test case checking time taken to send data to the cloud

B. Test Objective: The time taken to initialize GPS Module

\begin{tabular}{|l|l|l|}
\hline $\begin{array}{l}\text { TEST } \\
\text { CONDITION }\end{array}$ & OUTPUT SPECIFICATION & OPTIMAL \\
\hline $\begin{array}{l}\text { The time taken to } \\
\text { initialize the GPS module } \\
\text { to identify location } \\
\text { coordinates }\end{array}$ & $\begin{array}{l}\text { The microcontroller GPS module } \\
\text { takes 5min to 15min to identify } \\
\text { coordinates once the system is } \\
\text { powered on. Once the GPS } \\
\text { module fetches coordinates, data } \\
\text { is sent in real-time. }\end{array}$ & TRUE \\
\hline
\end{tabular}

Table 5: A test case for checking the time taken to initialize GPS 


\section{Test Objective: The time taken to relay patient data on App}

\begin{tabular}{|l|l|l|}
\hline $\begin{array}{l}\text { TEST } \\
\text { CONDITION }\end{array}$ & OUTPUT SPECIFICATION & OPTIMAL \\
\hline $\begin{array}{l}\text { The time taken to fetch } \\
\text { data from the cloud and } \\
\text { view it on App }\end{array}$ & $\begin{array}{l}\text { The time taken to run query } \\
\text { and relay information on the } \\
\text { app is <500ms }\end{array}$ & TRUE \\
\hline \multicolumn{2}{|l|}{$\begin{array}{l}\text { Table 6: A test case for checking the time taken to fetch data from the cloud } \\
\text { and rely on web }\end{array}$}
\end{tabular}

\section{Test Objective: The time taken to relay patient data to} Microcontroller

\begin{tabular}{|l|l|l|}
\hline $\begin{array}{l}\text { TEST } \\
\text { CONDITION }\end{array}$ & OUTPUT SPECIFICATION & OPTIMAL \\
\hline $\begin{array}{l}\text { The Time taken to fetch } \\
\text { data from sensors to } \\
\text { Microcontroller }\end{array}$ & $\begin{array}{l}\text { The Time taken to } \\
\text { fetch data from the } \\
\text { sensor and relay } \\
\text { information to } \\
\text { Microcontroller is } \\
\text { <50ms }\end{array}$ & TRUE \\
\hline
\end{tabular}

Table 7: A test case for checking the time taken to fetch data from the sensor to Microcontroller

\section{E. Test Objective: The time is taken to send SMS alert by GSM Module}

\begin{tabular}{|l|l|l|}
\hline $\begin{array}{l}\text { TEST } \\
\text { CONDITION }\end{array}$ & OUTPUT SPECIFICATION & OPTIMAL \\
\hline $\begin{array}{l}\text { Time taken to send an } \\
\text { SMS alert. }\end{array}$ & $\begin{array}{l}\text { API sends SMS alerts to } \\
\text { doctors and caretakers in real- } \\
\text { time. }\end{array}$ & TRUE \\
\hline
\end{tabular}

Table 8: A test case for checking the time taken to send SMS alert

\section{F. Test Objective: The time is taken to display patient history data on App}

\begin{tabular}{|l|l|l|}
\hline EST & OUTPUT SPECIFICATION & OPTIMAL \\
\hline $\begin{array}{l}\text { Time taken to display } \\
\text { patient vitals history } \\
\text { data. }\end{array}$ & $\begin{array}{l}\text { Firebase API displays the } \\
\text { history of a patient's data in } \\
\text { real-time. This scenario has } \\
\text { been tested with a mock data } \\
\text { dump of }>100000 \text { records and } \\
\text { the system can relay data on } \\
\text { the app in one second. }\end{array}$ & TRUE \\
\hline
\end{tabular}

Table 9: A test case for checking the time taken to displays the patient history

\section{CONCLUSION}

The main objective of the experiment was completed. All the modules like the Pulse detection module, GPS module, etc. and remote viewing module gave out the expected results. The proposed system modules can further circuit. The important fact that during project design is that all the hardware components used in the remote health detection system are easily available. Microcontrollers have turned out to be moderate, have expanded power proficient, scaleddown, and handling speeds. This has expanded the advancement of inserted frameworks that the human services innovations are receiving. These inserted frameworks have additionally been utilized in versatile innovation. Also, with expanded web use in most creating nations through advanced mobile phones, and with the utilization of IoT will wind up received at a faster rate. The human services framework remotely uses these plans to concoct an innovation for the better nature of living for individuals in the public arena. From a technology perspective, the project has seen concepts acquired through computer science and embedded study period being practically applied. The Electric circuit analysis knowledge was used during the design and fabrication of the individual modules. Electromagnetic fields analysis used in the wireless transmission between microcontrollers and Software programming used during the programming of the microcontrollers to come up with a final finished circuit system

\section{REFERENCES}

"The Internet of Things in healthcare: an overview" https://scholar.google.com/citations?user=Y4opLB8AAAAJ\&hl= en [Sept. 7, 2017]

"Envisioning inclusive futures: technology-based assistive sensory and action substitution"

https://www.infona.pl/resource/bwmeta1.element.elsevier3d45bfdd-fe55-359f-84e4-674a21 cae024 [Sept 4, 2017]

"A multiple communication standards compatible IoT system for medical usage"

http://ieeexplore.ieee.org/document/6577775/?reload=true [Sept 5, 2017]

"Ubiquitous data accessing method in IoT-based information system for emergency medical services"

https://www.deepdyve.com/lp/institute-of-electrical-andelectronics-engineers/ubiquitousdata-accessing-method-in-iotbased-information-system-for-YCZzyY5W9g [Sept 6, 2017]

"Acquisition and management of biomedical data using Internet of Things concepts"

http://ieeexplore.ieee.org/document/7050625/ [Sept 10, 2017]

"Real-time internet application with distributed flow environment for medical IoT" https://csdl.computer.org/csdl/proceedings/icgciot/2015/7910/00/ 07380578-abs.html [Sept 11, 2017] 